\title{
SOBRE LA CAPACIDAD DEL PENSAMIENTO PARA SOSTENER EL CUERPO COMO PROBLEMA
}

\author{
About the capacity of thought to sustain the body as a problem \\ Felipe Roblero Valenzuela \\ Universidad Diego Portales, Santiago, Chile \\ firoblero@gmail.com
}

\begin{abstract}
Resumen
Basándose en una reflexión respecto a cómo en filosofía se construyen los problemas como objeto del pensamiento, el artículo pretende reflexionar en torno a la dificultad que aparece si se le niega a la reflexión la posibilidad de aprehender la verdad. Si se siguen al pie de la letra las instrucciones de Lacoue-Labarthe el pensamiento tan solo produce ficciones, por lo que sus problemas no se estatuyen en la dilucidación de una verdad. Sin embargo, ¿cuál es la función de un pensamiento que produce ficciones? ¿Cómo se relaciona con los objetos a los cuales se dirige? Bajo la dirección de Deleuze se buscará una salida que implicará sostener al cuerpo como noción necesariamente implicada en un pensamiento no dirigido a la verdad, por lo que se sostiene la hipótesis de que el pensamiento como ficción podría ser concebido únicamente a partir de la arquitectura de un cuerpo de multiplicidades.
\end{abstract}

Palabras clave: ficción, verdad, cuerpo, pensamiento.

\begin{abstract}
Based on a reflection on how problems are constructed in philosophy as an object of thought, the article aims to reflect on the difficulty that arises if reflection is denied the possibility of apprehending the truth. If the instructions of Lacoue-Labarthe are followed to the letter, thought only produces fictions, so that their problems are not established in the elucidation of a truth. However, what is the function of a thought that produces fictions? How does it relate to the objects to which it is directed? Under the direction of Deleuze, an exit will be sought which will involve sustaining the body as a notion necessarily implied in a thought not directed to the truth, for which the hypothesis is that thought as fiction could be conceived solely from the architecture of a body of multiplicities.
\end{abstract}

Keywords: fiction, truth, body, thought.

Fecha de Recepción: 01/07/2019 - Fecha de Aceptación: 26/11/2019 


\section{Introducción}

El presente escrito no es más que un delirio. Se desenvuelve en un movimiento que no culmina, no pretende una solución, tan sólo erige múltiples problemas. Su arquitectura es delirante, acaba tan solo en preguntas que no logra responder por su naturaleza movediza. Sin embargo, circunscribe un tema que lo ciñe, el del cuerpo, pese a que no sea más que mediante largos rodeos. Con ellos, intenta enunciar una pregunta que no hace más que escapar. Por su naturaleza escurridiza, su formulación podría presentarse como sigue: ¿en qué sentido el cuerpo puede sostenerse como problema atingente al pensamiento? Sin embargo, aquella no es precisamente su pregunta.

Mediante cuatro momentos específicos, el presente artículo intenta reconstruir una pregunta sobre el pensamiento y su relación sobre el cuerpo, recurriendo principalmente a la obra de Deleuze y Lacoue-Labarthe para construir su recorrido. El paso por ambos autores rige el intento por vislumbrar cómo el pensamiento puede aprehender al cuerpo como objeto, sin embargo, el modo de establecer la pregunta sufrirá intensas torsiones en cada uno de los movimientos del texto. El esquema de este problema, siempre delirante, se detiene específicamente: en primer lugar, en la imagen del pensamiento, en tanto brinda una forma determinada al pensar; en segundo lugar, la relación del pensamiento y la ficción; en tercer lugar, en cómo se constituye el cuerpo en tanto problema y, en cuarto lugar, a la pregunta por la posibilidad de un problema sin solución. Estos cuatro momentos del escrito darán cuenta, en su recorrido, de la posibilidad de aprehender el cuerpo en tanto aprendizaje, situando precisamente ahí la aparición del pensamiento. Sin embargo, tal pensamiento no será ya meramente conceptual o racional, sino más bien un motor aberrante que le brindará la potencia para movilizarse de manera violenta, transformándolo.

\section{Primer movimiento: La imagen del pensamiento}

En Diferencia y repetición, Deleuze, mediante un gesto de sutileza espeluznante, refiere: "El pensamiento conceptual filosófico tiene por presupuesto implícito una Imagen del pensamiento, prefilosófica y natural, tomada del elemento puro del sentido común" (1968 204). Es un movimiento sutil que, sin embargo, sonsacará una diferencia: la conceptualidad propia de la reflexión no parece más que repetir lo ingenuo del sentido común. Es ahí donde se situará la trampa de todo pensamiento, tal como sería posible concebirlo coloquialmente, tanto su génesis como su movimiento poseen como fundamento la misma imagen respeto a cómo se debe pensar: "De acuerdo con esta imagen, el pensamiento es afín a lo verdadero, posee formalmente lo verdadero y quiere materialmente lo verdadero. 
$Y$ es sobre esa imagen que cada uno sabe - se supone que sabe - lo que significa pensar" (Deleuze 1968 204). Es decir, la imagen que el pensamiento proyecta ante la pregunta ¿qué significa pensar?, lo que presupone, es su afinidad con la verdad, su pretensión de aprehender lo verdadero como la finalidad de su movimiento.

La fuerza de esta afinidad supuesta entre el pensamiento y lo verdadero, bajo la figura del sentido común, adquiere una peligrosa potencia al ser naturalizada: "bajo la forma de un pensamiento natural que permite a la filosofía darse aires de que comienza y de que comienza sin presupuestos" (Deleuze 1968 202). Es decir, la trampa queda diseñada al erigirse una presunta naturalidad de aquella imagen que no prejuzgaría nada sobre el comienzo de su proceso de pensamiento:

El filósofo procede con más desinterés, es verdad, lo que él plantea como universalmente reconocido es tan sólo lo que significa pensar, ser y yo [moi], es decir, no un esto, sino la forma de la representación o del reconocimiento en general (Deleuze 1968 203).

La naturalidad con la cual el filósofo reflexiona descansa sobre esta imagen que habilita un procedimiento desinteresado que ya reconoce los ejes sobre los cuales se distribuirá el plano de su pensamiento. La forma de la representación, de la ipseidad de estos ejes, denota cómo dicha imagen actúa en su trasfondo, se operacionaliza para vislumbrar la verdad como su único vector. Ahora bien, este movimiento, pese a la ingenuidad que pretende evocar el sentido común, deja entrever una estrategia perversa; denota distribuciones específicas que actúan a modo de directrices implícitas en su desarrollo:

Mientras el pensamiento quede sometido a esta imagen que ya prejuzga acerca de todo, tanto acerca de la distribución del objeto y del sujeto como acerca del ser y del ente, tiene poca importancia que la filosofía comience por el objeto o por el sujeto, por el ser o el ente (Deleuze 1968 204).

De pronto, la supuesta ingenuidad queda al descubierto, exponiendo su afán por reconocer(se) en aquella imagen; es decir, no es significativo cuál sea el elemento que circunde la reflexión, ya sea el sujeto u el objeto lo pretendido, el mismo trasfondo será reconocido, su verdad fue estatuida en un movimiento previo, en el cual la imagen de este pensamiento actúa de modo subrepticio para volver a encontrarse en todos sus rodeos. Su verdad está consolidada de manera previa al movimiento de la reflexión, por lo que el comienzo no es tanto un principio como una operación repetida, desgastada, que tiende hacia el encuentro de lo mismo.

Esta configuración del pensamiento pierde su formato ingenuo al presentarse bajo la noción de cogito, reificando así aquella relación específica entre el pensamiento, sujeto y objeto en la superficie de una forma unitaria: 
Tal es el sentido del Cogito como comienzo: expresa la unidad de todas las facultades de relacionarse con una forma de objeto que refleja la identidad subjetiva; da un concepto filosófico del sentido común; es el sentido común convertido en filosófico (Deleuze 1968 207).

Este sentido, por tanto, constituye su fundamento y le presenta su forma de derecho al pensamiento, con la cual el sujeto transparente aprehende objetos y pretende su verdad. Es decir, apuntalada en el sentido común se erige la imagen que guiará al pensamiento hacia un saber acabado, en tanto se edifica sobre formaciones preestablecidas subrepticiamente. Sin embargo, esta arquitectura del pensar no es diferente a un movimiento estático que se ciñe a un modelo de identidad ergonómica: diseña sus herramientas en base a determinaciones humanas específicas en base a las cuales se pretenderá trabajar.

Volviendo a la pregunta inicial, al tomarse el cuerpo como objeto del pensamiento no se pretende sino aprehender la imagen ergonómica del pensamiento. Con esto se quiere decir que la reflexión lo inscribe, en el mismo movimiento que lo toma como objetivo, en su determinación correspondiente, esto es, como objeto cerrado en sus contornos específicos que delimitan su ipseidad, sin chorreos ni fugas significativas. Sin embargo, esta línea que lo constriñe como idéntico a sí, no es más (ni menos) que el reflejo del mismo pensamiento, una operacionalización de la imagen. En aquel fulgor de la reflexión se pretende aprehender su esencia, pese a que, tal vez, se alcance únicamente aquello que ya estaba escondido tras un arbusto y, en su aparecer, se establece como una verdad. En consecuencia, destaca cómo se sostiene el pensamiento sobre la cuestión de la verdad, previo a cualquier movimiento esta pretensión ya está enganchada; por lo cual la pregunta que se dirime consiste en cómo, con que método, aprehender su verdad. En este caso el problema del cuerpo es subsumido de modo autónomo a la dialéctica de su verdad, para converger en la cuestión de su esencia o su finalidad teleológica.

\section{Segundo movimiento: El pensamiento y la ficción}

En "La fábula (literatura y filosofía)", Lacoue-Labarthe parece formular un tenue giro en el modo de situar las coordenadas del problema, atingente para dilucidar la forma bajo la que se desenvuelve el movimiento del pensamiento. Con esta referencia, se pretende evocar ciertas luces sobre cómo pensar el cuerpo, descentrado de las trampas de la imagen del pensamiento. ¿Es posible situarlo en otro territorio, con otra relación a la verdad?

En las primeras líneas de este texto, Lacoue-Labarthe vuelve a poner sobre la mesa la forma del pensamiento filosófico: “Querríamos plantearle aquí a la 
filosofía la cuestión de su "forma"; o, más exactamente, arrojar sobre ella esta sospecha: ¿y si, después de todo, no fuera más que literatura?" (135).

Con estas intempestivas palabras, da comienzo a un texto que pone en el centro de atención a la filosofía, caracterizada por la pretensión de un decir sobre la verdad, y la literatura, incapacitada de este decir puro. La tensión entre ambos se teje desde el momento en que la intención de producir un decir transparente mediante la primera, supedita a la segunda al peyorativo rótulo de ficción (castrada del acceso a la verdad y ajena a los problemas importantes). Sin embargo, bajo la invocación del texto nietzscheano, el movimiento del escrito hace emerger un descentramiento inquietante que huele a dinamita, recurriendo a la tradición filosófica para sustentar el embrollo que quiere desarrollar: "Parménides dijo: No se piensa lo que no es - ; nosotros estamos en el otro extremo y decimos: - lo que puede ser pensado debe ser ciertamente una ficción-"' (Nietzsche, en LacoueLabarthe 138).

Con la referencia a Parménides resurge la cuestión de la forma-filosofía, que se originaría en el pensamiento del filósofo griego para finalizar con un alemán, Hegel, distribuyendo comienzo y culminación absoluta. Con esto sitúa la discusión del Ser y el pensamiento en una tradición específica que es considerada como una unidad que, con Hegel, culminará en el reconocimiento de lo Mismo en lo Idéntico, movimiento que da fin a la historia (Lacoue-Labarthe 139). Se instaura, a partir de ahí, un discurso que tiene la capacidad y la finalidad de decir la verdad y que, bajo sus principios precisamente justificados, no piensa (no puede pensar) lo que no es. Ahora bien, con esta referencia nietzscheana Lacoue-Labarthe pretende buscar una vía de escape a la direccionalidad teleológica del desenvolvimiento del espíritu. Por tanto, es necesario realizar la pregunta: ¿Qué quiere decir que Nietzsche se posicione en el otro extremo, homologando el pensamiento a la ficción?

Se delinea una interrogante muy precisa que arremete contra la imagen de la ficción y su posibilidad de hablar un lenguaje otro, ajeno al de una dialéctica que fundamenta todo conocimiento como verdad. Para rodearla, necesita circunscribir el concepto de ficción, ya que es extraño al sentido común e, incluso, asoma un fondo nocturno cuanto menos inquietante. Sin embargo, al situar en el ojo del huracán a la ficción para alejarse de un discurso centrado en la verdad, se revela una primera advertencia: la misma pregunta por situar la ficción en contraposición a la verdad lo estatuye como su negativo, en tanto no-verdad, por lo cual se operacionaliza en relación dialéctica con el logos.

Es decir, la misma formulación erige su dificultad, si se habla de ficción se inscribe la dimensión de lo falso, ficticio y, en definitiva, no verdadero. Entonces, si con Nietzsche el mundo ha devenido ficción y Dios ha muerto, tan solo se invierte el asunto, lo que antes era verdad ahora es falso, la apariencia se eleva como nueva verdad y aún reina la luminosidad diurna del sentido. Incluso Crepúsculo de los 
ídolos parece ir en esta dirección: "El mundo aparente es el "único": el "mundo verdadero" no es más que un añadido mentiroso" (Nietzsche 1889 52). Por lo tanto, el crepúsculo divino presenta una opacidad en la que aún rige el imperio de la luz, crepúsculo más bien iridiscente. Así, el problema de la contraposición ficticioverdadero no pierde fuerza, sino que es potenciado con la inversión del platonismo. Este se ciñe a la atribución de veracidad en la dinámica continuo devenir de las apariencias, realización de la metafísica misma y cierre estable que se expresa de modo continuo entre el ser y el ente.

Aun así, el motor sigue siendo el sentido de las cosas, el paso entre el régimen la existencia a la esencia bajo la formulación del sentido. Pese a que tenga el aspecto de un cambio, el sentido ordena lo negativo de la existencia y el aparecer de las cosas; aún más, pese a verse un tanto movedizo, la tranquilidad, sigue manteniéndose como finalidad del proceso del logos que trae el lenguaje. Esto refleja, únicamente, el mismo interjuego de superficies orden-caos, ordenamiento aún unitario que va constituyendo una especie de verdad. Sin embargo, pensarordenar las apariencias para establecer una verdad que domina y tranquiliza el devenir, bajo la figura del eterno retorno, es un movimiento estéril, ya que, de algún modo, aún se adhiere al establecimiento de verdades bajo el problema del cómo domino, cómo organizo, cómo le brindo al objeto la unidad mínima del sujeto. La existencia debe ser organizada, la tensión del caos y el abismo debe ser puesta en su lugar. Así, arriesgando una redundancia excesiva, el problema de la verdad sigue siendo la fuerza centrífuga para el pensamiento, su sentido.

Pese a encontrar la misma gran trampa en el pensamiento de Nietzsche, tal como se explicitó respecto a Crepúsculo de los ídolos, Lacoue-Labarthe evoca otra ficción, Zaratustra, intentando buscar un escape, una línea de fuga al problema teológico. Para ello cita nuevamente al filólogo alemán: "El mundo-verdad lo hemos abolido. ¿Qué mundo nos queda?, ¿Quizás el mundo de las apariencias?... ¡No! ¡Con el mundo-verdad hemos abolido también el mundo de las apariencias!” (Nietzsche 1889 58). Con esta sentencia el remezón es mayor: en la pretensión de dinamitar el mundo-verdad se hace necesario también erradicar la apariencia. Al momento de devenir fábula, el mundo ya no se invierte, sino que se desprende la oposición problemática entre verdad y mentira, la cual se ve teñida como discurso moral. Este devenir se plantea como anulación del inicio marcado por el Logos, desprendido de aquella imagen ergonómica del pensamiento, la creación es anulada; no se ha matado a Dios, siempre estuvo muerto. "El mundo se convierte en fábula porque ya lo era; o más exactamente lo era ya el discurso que lo constituía como tal" (Lacoue-Labarthe 1970 143).

Aquel poco espectacular salto, desengancha en cierto punto el estatuto del problema, el pensamiento se descentra de su relación específica con la verdad y el discurso queda liberado del decir puro hacia el decir, un decir que parece, no se 
opone a nada, no sostiene nada, no se refiere a nada sobre la verdad. Esto es un tanto aberrante, las consecuencias para la cuestión de cómo pensar el cuerpo y qué lo sostiene como problema parece perder peso. Es decir, en el caso en el cual el pensar no diverge del ficcionar, no hay vectores claros que indiquen qué o cómo reflexionar sobre el cuerpo, el problema se disuelve hacia un por qué pensarlo o, a la pregunta de debido a qué es necesario intentarlo. Haciendo eco a los párrafos finales del texto de Lacoue-Labarthe: ¿somos capaces de pensar el cuerpo como ficción? $\mathrm{O}$, al pensarlo, ¿somos capaces de mantenernos ateos en aquel intento? (154). El cuerpo ha perdido su unidad como objetivo para el pensamiento, ya no hay un cuerpo claro y distinto hacia el cual dirigirse al instante en que el pensamiento se desprende de su pretensión de verdad, lo cual disuelve también toda pregunta que movilice el pensar.

\section{Tercer movimiento: el cuerpo como problema}

Al desengancharse pensamiento y verdad, con el devenir-fabula del mundo, se pierde un vector tradicional, trascendental, del pensamiento. Por tanto, es necesario reflexionar sobre qué sería esto, qué moviliza la producción de ficciones. Parece necesario cuestionar la noción de problema: ¿qué es un problema para un pensamiento desenganchado de la lógica trascendental de la verdad?

Al dirigirse a este complejo asunto, Deleuze (1968) desplaza algunos elementos. En el pensamiento orientado hacia la verdad, el problema queda supeditado a la veracidad de los contenidos proposicionales (241). Es decir, la constitución del campo de lo problemático se esquematiza en la matriz dialéctica del sujeto-objeto y su relación: ¿x es o no es? En ella, el ser es el lazo originario y también el límite, comienzo y fin de toda la operación. Ahora bien, si el mundo deviene ficción se agrieta algo de esta unidad; el entrelazado del ser no puede formular la pregunta hacia la verdad y el pensamiento pierde su centro. Por lo tanto, es preciso abandonar el problema proposicional al mismo tiempo que se debe erigir la pregunta por la génesis singular de un pensamiento, con la cual sea posible sostener aún alguna pregunta: "Como no se advierte que el sentido o el problema es extraproposicional, que difiere por naturaleza de toda proposición, se descuida lo esencial, la génesis del acto de pensar" (Deleuze 1968 241).

Una génesis tal se presenta únicamente en una dinámica del encuentro con lo aberrante de una diferencia que hace resonar lo pasivo en el pensamiento para interpelarlo. Esto quiere decir, el pensamiento no construye al problema, todo lo contrario, el problema cuestiona al pensamiento, lo fuerza a movilizarse tal como el trauma inaugura un ideal de ligazón afectiva. La génesis singular del acto de pensar puede ser vislumbrada si se examina la facultad del pensamiento a la luz de la emergencia de un encuentro con lo diferencial, con la Idea: "Los problemas son 
las Ideas mismas [...] las Ideas por sí mismas son problemáticas, problematizantes" (Deleuze 1968 257). Esta no es más que una multiplicidad sin identidad previa, la indeterminación propia de una multiplicidad de elementos diferenciales encarnados en una relación, ella misma, diferencial, que no tiende a la unidad (278).

Bajo las máscaras de Deleuze y Lacoue-Labarthe se asoma algo extraño; el mundo como ficción rompe el lazo proposicional advenido con la imagen del pensamiento. El campo problemático se aproxima al acontecimiento, a la génesis del pensamiento en el encuentro con la diferencia. Sin embargo, para aprehender dicha génesis, entendida como proceso de producción de pensamientos, debe habilitarse un movimiento que no sea el de lo mismo; romper con la unidad atómica e invocar la aparición de esta instancia diferencial que presenta la Idea como horizonte.

En relación con lo anterior, surge la ligera sospecha de que no se está hablando sino de cuerpo, un cuerpo otro, diferencial, movilizado por chorreos intensivos y ya no cuerpo cerrado en sí, bajo el modelo de un objeto claro y distinto. Es decir, la génesis del pensar se ve arraigada al encuentro con lo diferencial de la Idea, la cual no es más que la operatividad de la función de la multiplicidad. En palabras de Deleuze:

Las Ideas son multiplicidades, cada Idea es una multiplicidad, una variedad [...] la multiplicidad no debe designar una combinación de lo múltiple y lo uno, sino, por el contrario, una organización propia de lo múltiple como tal, que de ningún modo tiene necesidad de la unidad para formar un sistema (1968 276-277).

Es decir, sostener una pretensión de apertura en la Idea implica romper con la unidad, fisurar el origen, desgarrando la lógica dialéctica de lo múltiple y lo uno. Afirmar la ficción implica soportar, por tanto, la multiplicidad, encarnarla en un pliegue cuerpo-problema que deviene activo, constante e irreductible al mismo tiempo que forma sistemas o conjuntos vivos que tienden a cierta estabilidad.

La Idea, entonces, sitúa una ineludible dimensión espacial, emerge en tanto problemática bajo una dinámica del encuentro, fulgurando como acontecimiento genético violento. Este desplazamiento del pensamiento queda expuesto así a la multiplicidad intensiva. Ahora bien, siguiendo la lógica que plantea el autor, este tipo de multiplicidad consiste en elementos singulares en relación de pura exterioridad, sin interioridad, "son distancias indivisibles", infinitos actuales, conjuntos intensivos (Deleuze 2008 408). Se propone aquí un lugar preciso, la Idea emerge en el espacio que se habilita con la instanciación de conjuntos intensivos que forman sistemas o máquinas, los cuales, encarnados, conjuran cuerpos 
vivientes y movedizos, implicados unos con otros, potencias que se afectan mutuamente al diferenciarse.

La génesis del pensamiento se ve impulsada de modo violento por el interjuego de afectaciones, de cuerpos que se ven afectados por otros al mismo tiempo que afectan, que en un movimiento de determinación son determinados, una especie de pensamiento material o materia pensante; de todos modos, pensamiento producido en la inmanencia de un encuentro que acontece en constante devenir o transitar. La irremediable violencia del pensamiento no es, sino, la violencia del porvenir. Por tanto, emerge un pensamiento como producción, que está encarnado, pero, también, atravesado y fisurado por el tiempo del devenir. Curiosamente, este desplazamiento del pensamiento lo ha desenganchado del problema de la verdad del cuerpo para presenciar una dimensión constitutiva de este: es el cuerpo del problema, el cuerpo como ficción. "En suma, la determinación completa de un problema se confunde con la existencia, el número, la distribución de puntos determinantes que proveen precisamente sus condiciones" (Deleuze 1968 270).

En la génesis del pensamiento, "el Cogito recupera toda la potencia de un inconsciente diferencial, inconsciente del pensamiento puro [...] que pone en el pensamiento como tal algo no pensado, sin lo cual ese ejercicio sería imposible y vacío para siempre" (Deleuze 1968 265). Tal como se mencionó, con el giro que desvanece el cuerpo como objeto ergonómico, se desgarra también la imagen del pensamiento, introduciéndose lo no pensado en toda posibilidad de pensar. Con ello se destituyen los límites que posibilitan discernir un comienzo o un final de su movimiento. Dios siempre estuvo muerto, el mundo siempre fue fábula sin origen, repetición eternizada. La ficción, entonces, pliega cuerpos y pensamientos enmarañándolos para en la producción de sistemas vivientes y descentrados, pero con un sentido productivo incesante:

Toda máquina es máquina de máquina. La máquina sólo produce un corte de flujo cuando está conectada a otra máquina que se supone productora de flujo. Y sin duda, esa otra máquina es, en realidad, a su vez corte. Pero no lo es más que en relación con la tercera máquina que produce idealmente, es decir, relativamente, un flujo continuo infinito. Así por ejemplo, la máquina-ano y la máquina intestino, la máquina intestino y la máquinaestómago, la máquina-estómago y la máquina-boca, la máquina-boca y el flujo del rebaño (y además, y además, y además...) (Deleuze 1972 42).

\section{El campo de un problema sin solución}

La pregunta por cómo pensar el cuerpo se deslizó hacia la posibilidad de la ficción $\mathrm{y}$, con ello, terminó afirmando como necesaria la multiplicidad: cuerpos múltiples que se individúan constantemente en una repetición eterna de perspectivas divergentes, cuerpos que afectan, determinan $y$, a la vez, son afectados, 
determinados. Esto quiere decir que el espacio de la diferencia produce intempestivamente perspectivas corporales, encarnadas $\mathrm{y}$, en ese mismo movimiento, el espacio es producido, en una enmarañada confusión o pliegue sin origen ni fin. La génesis de la instancia problemática es corpórea, pero este ya no es un cuerpo objetivo, determinado o alienado, constituido de una forma precisa:

El eretismo, la excitación, la agitación que turba o confunde el cuerpo lo hace olvidar que es una bomba atómica, Anatomizado, parasitado, sexualmente ligado, unido, fijado, diferenciado, el cuerpo alienado ya no sabe que es un infinito encadenamiento de cuerpos, de espíritus, de lenguas extranjeras, desconocidas y todavía inexistentes o inhumanas. Ya no sabe que se excede a sí mismo, que es en sí mismo un cuerpo heterogéneo (Margel 2008 24).

Ahora bien, si se retoma la pregunta guía de la presente reflexión, ¿por qué sostener el cuerpo como un problema atingente al pensamiento? Pues bien, no es posible sostenerlo sin plegarlo con el problema que inaugura el pensar. Es decir, el cuerpo se derrama en la instancia problemática, moviliza de modo inquietante y forzado al pensar, es el cuerpo plegado en el pensamiento quien interroga y sostiene los problemas. Sin embargo, dicha instancia problemática no pretende con apremio una solución que la clausure, sino más bien inaugura un campo que produce el movimiento.

Que la instancia problemática habilite un campo constituyente de soluciones quiere decir que el problema ya no posee una fuerza centrífuga en la verdad. Este no se clausura en superficies cerradas del tipo proposicional, el sentido no está en una direccionalidad teleológica. Al contrario, el problema no tiene cierre, es eternamente constituyente, pero, en su constante constituir objetos de pensamiento, erige campos de solución al organizar sistemas y encarnar cuerpos, tiene una naturaleza movilizante, la del devenir:

En relación con sus soluciones, el problema es trascendente e inmanente a la vez. Trascendente, porque consiste en un sistema de lazos ideales o de relaciones diferenciales entre elementos genéticos. Inmanente, porque esos lazos o relaciones se encarnan en las relaciones actuales que no se le asemejan y que se definen por el campo de solución (Deleuze 1968 250).

La solución expresa el problema a la vez que lo determina, es decir, al constituir cortes abre líneas de flujo, en una coreografía eterna que encadena series o movimientos heterogéneos que dinamitan identidades y produce una danza de escorzos; espacios de producción intempestiva. El campo solución, ficticio también, se desenvuelve y vuelve a plegar, es un texto, es pintura, es teatro que nada clausura. Bajo aquella máscara sólo encuentra la producción de más máscaras que reflejan el problema vital, el movimiento del devenir productivo de sentidos 
vectorizantes. Esto, sin embargo, no erradica el campo del saber, tal vez solo lo desinfla, hace un agujero en él para moverlo de su posición de finalidad, tal como Nietzsche denuncia en sus textos tempranos: "En la naturaleza no hay nada tan despreciable y ruin que no pueda ser inflado como un odre por las fuerzas del conocimiento, con un pequeño soplido" (Nietzsche 2018 19).

Por otro lado, el conocimiento descentrado muta y se transforma el aprendizaje, "pues el aprendiz, por una parte, es aquel que constituye e inviste los problemas prácticos o especulativos en tanto tales. Aprender es la palabra que conviene a los actos subjetivos que se realizan frente a la objetividad del problema (Idea)" (Deleuze 1968 251). Esta es la solución que abre caminos, constituye una arquitectura, pero no soluciona nada en términos de verdad o falsedad, es decir, no descubre esencia alguna. El problema se instancia en el cuerpo a modo de aprendizaje, tal es su solución como movimiento del pensamiento. Nietzsche, en Acerca de la verdad y la mentira en sentido extramoral, no deja de señalar una perspectiva semejante:

El intelecto, ese maestro de la simulación, queda libre entonces [...] es allí más exuberante, rico, orgulloso, diestro y audaz que nunca: con satisfacción creadora mezcla desordenadamente las metáforas y cambia de sitio los linderos de la abstracción[...] habla en puras metáforas prohibidas y en una disposición de conceptos jamás escuchada, para corresponder creadoramente -mediante la destrucción y escarnio de las viejas divisiones conceptuales-, por lo menos a las impresiones de las poderosas intuiciones actuales (2018 32-33).

La pregunta del pensamiento por el cuerpo evoca una dimensión afirmativa, llama a sostener y determinar problemas, a expresarlos y desenvolverlos para encontrar nuevos pliegues, siendo este un proceso de producción vital más allá de cualquier supeditación a la teleología o al utilitarismo. Si se erige este problema, el pensamiento se ve obligado, necesariamente, a afirmar la multiplicidad, generando un movimiento creativo que culmina en un aprendizaje. El pensamiento realiza este movimiento, se instancia en un aprendizaje corpóreo, pero no encuentra la respuesta a su pregunta, pues la pregunta se disuelve antes de encontrar una forma precisa.

\section{Bibliografía}

Deleuze, Gilles. Diferencia y repetición. Buenos Aires: Amorrortu Editores, 1968.

Deleuze, Gilles. El Anti Edipo. Barcelona: Paidós, 1972.

Deleuze, Gilles. En medio de Spinoza. Buenos Aires: Cactus, 2008. 
Lacoue-Labarthe, Philippe. "La fábula (Literatura y Filosofía)", Poetique 1 (1970): 135-154.

Margel, Serge. Alienación. Santiago: Metales Pesados, 2008.

Nietzsche, Friedrich. Crepúsculo de los Ídolos o Cómo se filosofa con el martillo. Madrid: Alianza, 1989.

Nietzsche, Friedrich. Verdad y mentira. Valparaíso: Editorial UV, 2018. 